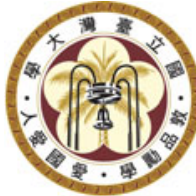

\title{
FACULTY AND RESEARCH
} SCHOLAR POSITIONS

Center for Condensed Matter Sciences

National Taiwan University

The Center for Condensed Matter Sciences (CCMS), a premiere research center at National Taiwan University, has immediate openings for regular faculty and non-tenure research scholar positions. Rank of faculty positions will match with the candidates' qualifications. Applicants with excellent credentials in cutting edge condensed matter research fields of electronic, optical, magnetic, quantum transport, biopolymer, and nanostructured materials, in both basic and applied aspects, will be considered.

Applicants should send resume, publication list, research plans, and three letters of recommendation to:

Director, Prof. Li-Chyong Chen

Center for Condensed Matter Sciences

National Taiwan University

Taipei 106, Taiwan, Republic of China

Center Assistant: Wei-Lin Chou

Email: cwli1828@ntu.edu.tw

Phone: (02) 3366-5201

Fax: (02) 2365-5404

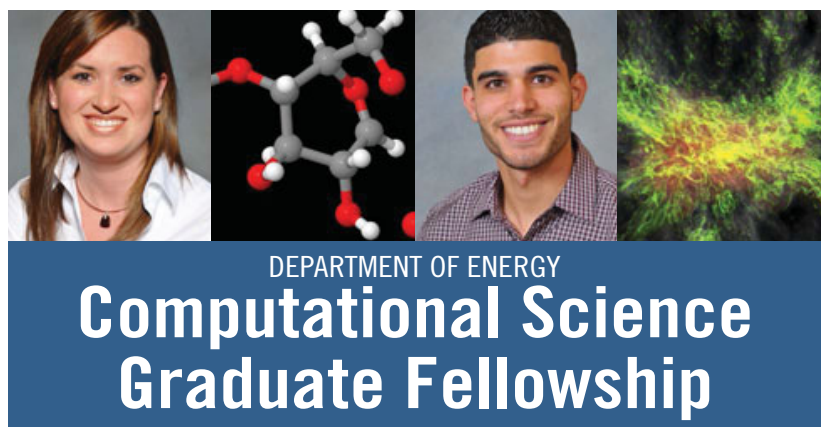

\section{PROGRAM HIGHLIGHTS}

$\$ 36,000$ yearly stipend

Payment of full tuition and required fees

$\$ 5,000$ academic allowance in first year

$\$ 1,000$ academic allowance each renewed year
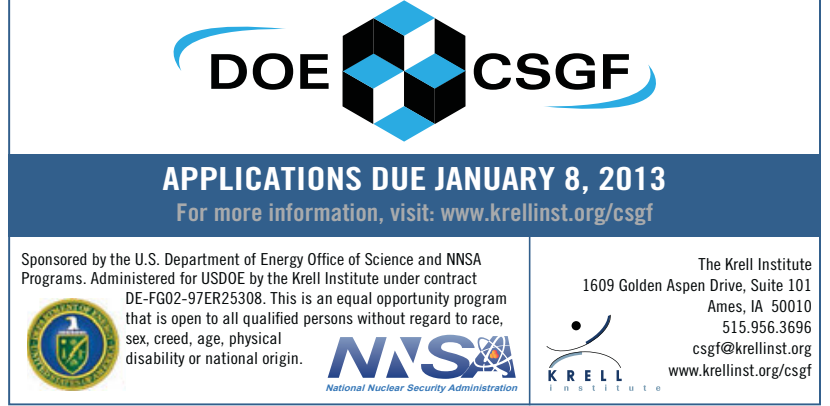

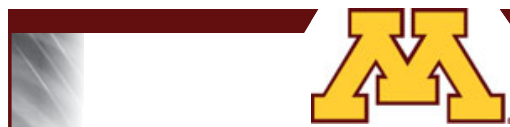

\section{TENURED OR TENURE-TRACK FACULTY POSITION}

Chemical Engineering and Materials Science University of Minnesota

The Department of Chemical Engineering and Materials Science at the University of Minnesota (www.cems.umn.edu) seeks to fill a faculty position at the Assistant (tenure-track), Associate, or Full Professor level, commensurate with experience. Outstanding candidates with a $\mathrm{PhD}$ degree in any area related to chemical engineering and materials science will be considered. Candidates should have a distinguished academic and research record and a commitment to teaching in a highly interdisciplinary department.

Applications, consisting of a CV (including a list of publications), a research plan, a teaching plan, and a list of three references with contact information (including email addresses), should be submitted on-line at https://employment.umn.edu. Search for requisition number 180484 . Review of the applications will begin immediately and continue until the position is filled. The successful candidate will be in place as early as Fall 2013.

The University of Minnesota is an equal opportunity educator and employer.

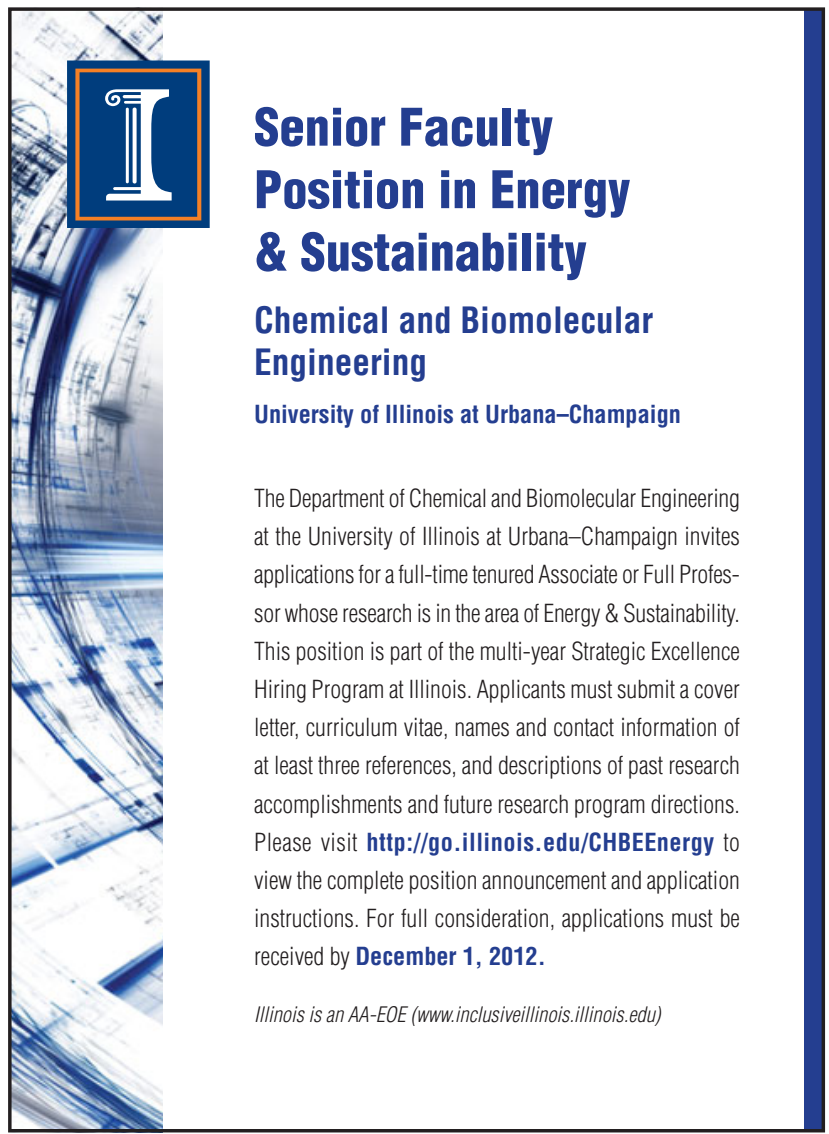




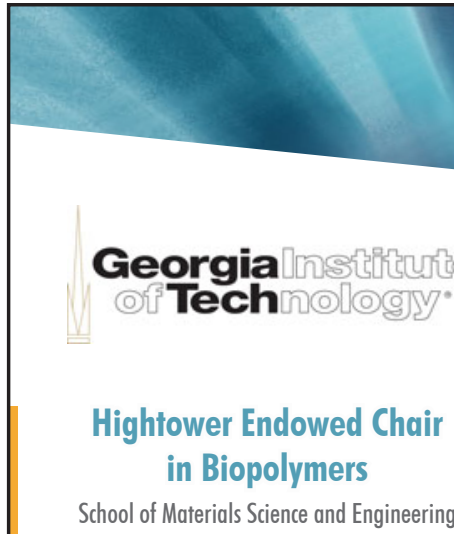

The School of Materials Science and Engineering at the Georgia Institute of Technology invites applications and nominations for the Hightower Chair in Biopolymers. This senior position will serve as a focal point within the School and the Institute for research and teaching in the field of biopolymers, while working to broaden interactions in polymer science, bio-materials, and polymeric materials having a biological origin or function. Candidates with interests in the theory, design, synthesis, processing, characterization, and applications of biopolymers, are especially encouraged to apply. There are numerous opportunities for campus-wide interactions in the various units of the Colleges of Engineering and Science, including the School of Applied Physiology and the Department of Biomedical Engineering. Further interactions are envisioned with the Parker H. Petit Institute for Bioengineering and Bioscience (IBB), the Strategic Energy Institute (SEI), and the Institute for Electronics and Nanotechnology (IEN).

The successful candidate should have a history of establishing outstanding research programs, a demonstrated interest in fostering collaboration, and a commitment to high-quality teaching with the opportunity to develop courses and academic programming in biopolymers. The metropolitan Atlanta region provides much opportunity for local cooperation in medical research and development, along with potential entrepreneurial opportunities through the Institute's (IC) program.

Candidates should submit an application letter describing their vision for the position, a curriculum vitae, and names (and contact information) for five references to www.mse. gatech.edu/Hightower. The application review process will begin immediately and will continue until the position is filled. Enquiries may be made to chair of the search committee at anselm.griffin@mse.gatech.edu. All enquiries and applications will be treated as confidential.

The Georgia Institute of Technology is an equal opportunity employer and welcomes
nominations and applications from women and minority candidates.

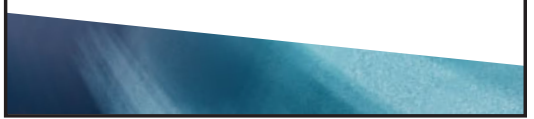

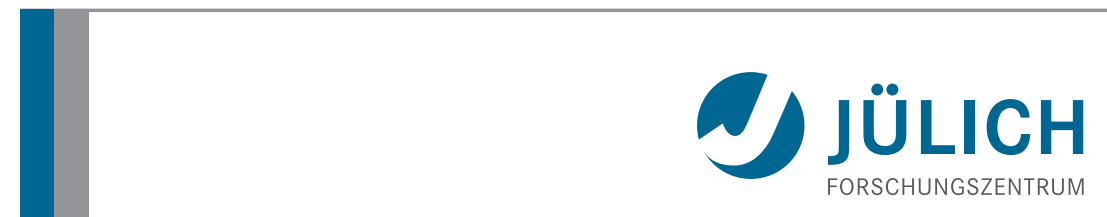

With a staff of 5000, Forschungszentrum Jülich - a member of the Helmholtz Association - is one of the largest interdisciplinary research centres in Europe and stands for the next generation of key technologies. Work with us on the grand challenges in the fields of health, energy \& environment, and information technology, as well as on the many and varied tasks of research management.

The Jülich Centre for Neutron Science (JCNS) provides scientists at universities and research institutions in Germany and throughout the world with access to neutron instruments of the highest performance class.

For planning and designing neutron scattering instruments for the future European Spallation Source (ESS), we currently have a vacancy for a

\section{PHYSICIST (f/m) (with PhD)}

\section{Job Description:}

The tasks comprise the development of concepts for and the conceptual design of neutron diffractometers and spectrometers proposed for the ESS. The optimization of the instrument parameters for operation at the ESS - a long-pulse neutron source - will be one of the priorities in this project. After an initial layout phase using an analytical approach, the proposed concepts and designs will be evaluated and optimized further by means of computer simulations. The main tools available for the simulations are the McStas and VITESS programs. Experiments to verify results will be performed at existing instruments and test beam lines at Garching (FRMII), Berlin (HZB) and Oak Ridge (SNS). The project requires close cooperation and coordination with the ESS-AB organization in Lund (Sweden).

\section{Your Profile:}

- $\mathrm{PhD}$ in physics

- Knowledge in the fields of scattering methods or optics

- Programming skills, particularly $\mathrm{C} / \mathrm{C}++$

- Very good command of English

- Ability to work in an interdisciplinary and international team

- Ability to work independently and on one's own initiative

- Willingness to undertake travel, sometimes for several days, to other research institutions in order to exchange information and perform experiments.

Our Offer:

- Challenging and varied work in an interdisciplinary and international team

- Employment initially for a fixed term of three years

- Opportunity to job share

- Salary and social benefits in conformity with the provisions of the Collective Agreement for the Civil Service (TVöD).

Place of employment: Garching (near Munich)

Forschungszentrum Jülich aims to employ more women in this area and therefore particularly welcomes applications from women.

We also welcome applications from disabled persons.

Please send your application following the specific requirements, quoting the reference code 227/2012MR to:

Forschungszentrum Jülich $\mathrm{GmbH}$

Geschäftsbereich Personal

- Personalentwicklung -

52425 Jülich

Germany

contact:

Barbara Kranen

phone: +49 $246161-9700$

www.fz-juelich.de 


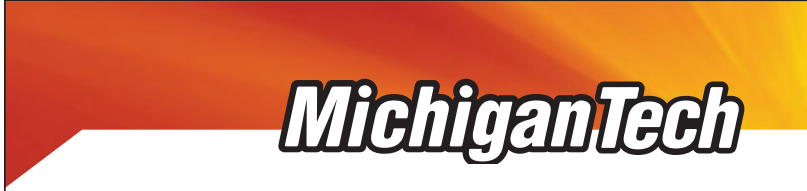

\section{FACULTY POSITION \\ Transportation: Concrete Materials}

Michigan Technological University is conducting a university-wide Strategic Faculty Hiring Initiative (SFHI) in Transportation. We invite applications for a tenure-track, faculty position in Concrete Materials.

Applicants are expected to integrate their research with existing strengths in transportation at Michigan Tech. The successful candidate will inspire and lead interdisciplinary collaboration amongst faculty with common interests in transportation, establish a nationally recognized research program, attract external funding, and extend their profile as a world-class scholar. Required qualifications include a PhD degree, prior success in obtaining external funding, demonstrated leadership skills, and a commitment to excellence in undergraduate teaching and graduate education. Applicants should specify their potential home department(s). Details on the hiring initiative (including required application materials and the submission process) are available at www.mtu.edu/sfhi.

Michigan Tech is an ADVANCE institution, one of a limited number of universities in receipt of NSF funds in support of our commitment to increase diversity and the participation and advancement of women in STEM.

Michigan Tech also has a Dual Career Program which assists departments with partner orientation to the university and community and identification of possible positions for partners (see www.dual.mtu.edu).

Michigan Technological University is an AA/EEO employer/educational institution

\section{FACULTY POSITION}

Department of Materials Science and Engineering University of California, Berkeley

The Department of Materials Science \& Engineering in the College of Engineering at the University of California, Berkeley, invites applications for a faculty position at the level of tenure-track assistant professor or associate professor with tenure. The expected start date is July 1,2013 . We seek an individual with demonstrated excellence in the broad area of electronic materials. Applicants must have a PhD degree by June 2013 or equivalent and evidence of outstanding scholarship within a relevant discipline. The successful applicant will run a world-class electronic materials research program, offer undergraduate and graduate courses in materials science and engineering, and have a strong commitment to university service and diversity.

Applications are accepted online at https://aprecruit.berkeley. edu/apply/JPF00013 and should include a curriculum vitae with a list of publications, a description of research and teaching interests, three representative peer-reviewed (or in review) publications, and a list of at least three references. If you are unable to access the online application website, e-mail us at wanda@berkeley.edu for the physical address to mail the application.

Formal review of applications will begin December 1, 2012. The closing date for applications is January 2, 2013.

The University of California is an equal opportunity affirmative action employer, committed to excellence through diversity. The college seeks candidates whose research, teaching, or service has prepared them to contribute to our commitment to diversity and inclusion in higher education. The college is also committed to addressing the family needs of faculty, including dual career couples and single parents. For more information please go the CALcierge website at http://calcierge.berkeley.edu/.

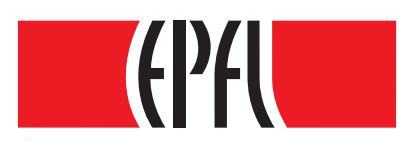

ÉCOLE POLYTECHNIQUE FÉDÉRALE DE LAUSANNE

\section{Faculty Position in Materials Science and Engineering} at the Ecole polytechnique fédérale de Lausanne (EPFL)
The School of Engineering of EPFL invites applications from candidates for a tenure-track assistant professor within its Institute of Materials. We seek exceptional individuals who will develop and drive a research program at the forefront of the discipline, who have a strong dedication to teaching at the undergraduate and graduate levels, and who will be proactive members of a vibrant Materials community.

Top-level applications covering all areas of materials science and engineering are invited with the following topics being of particular interest:

(i) electrochemistry as applied to the processing, microstructural tailoring or performance of materials,

(ii) the processing, microstructural tailoring, characterization or performance of materials having surface functionality, and

(iii) modeling and simulation as relevant to the processing, microstructural development and performance of materials.

Start-up resources and state-of-the-art research infrastructure will be available. Salaries and benefits are internationally competitive.

The EPFL, located in Lausanne, Switzerland, is a dynamically growing and well-funded institution fostering excellence and diversity. It has a highly international campus at an exceptionally attractive location boasting first-class infrastructure. As a technical university covering essentially the entire palette of engineering and science, EPFL offers a fertile environment for research cooperation between different disciplines. The EPFL environment is multi-lingual and multi-cultural, with English often serving as a common interface.

Applications should include a cover letter with a statement of motivation, curriculum vitae, list of publications and patents, concise statement of research and teaching interests, and the names and addresses of at least five referees. Applications must be uploaded in PDF format to the recruitment web site: imx-search13.epfl.ch

Formal evaluation of candidates will begin on 14 December 2012.

Enquiries may be addressed to:

Prof. Harm-Anton Klok

Search Chairman

e-mail: imx-search@epfl.ch

For additional information on EPFL, please consult the web sites: www.epfl.ch, sti.epfl.ch and imx.epfl.ch.

EPFL is committed to increasing the diversity of its faculty, and strongly encourages women to apply. 


\title{
PRINCETON UNIVERSITY \\ ASSISTANT PROFESSORSHIP \\ CIVIL AND ENVIRONMIENTAL ENGINEERING
}

\begin{abstract}
The Department of Civil and Environmental Engineering (http://www.princeton.edu/cee) at Princeton University invites applications for a tenure-track appointment at the assistant professor level, with the potential to be jointly appointed within the Andlinger Center for Energy and the Environment (http://www.princeton.edu/acee).

The ideal candidate will build upon current strengths in the Mechanics, Materials and Structures (MMS) program of CEE and interact closely with activities of the Andlinger Center, as well as with other key elements of the University community involved in research areas concerning energy and environment (including the Environmental Engineering and Water Resources program, School of Architecture, Princeton Environmental Institute, Princeton Institute for the Science and Technology of Materials (PRISM), Woodrow Wilson School, and other departments of the School of Engineering and Applied Sciences). The research area of particular interest is energy-efficient design of buildings. Other areas of potential interest include materials science for energy-efficient civil engineering systems, water and energy, and other areas in sustainable design of civil engineering systems.
\end{abstract}

The Department has a strong undergraduate program in structural engineering as well as in architecture and engineering, and a growing graduate program in structural engineering. Applicants should have interest in, and competence for, teaching broad undergraduate courses as well as advanced graduate courses in Civil Engineering. If jointly appointed in the Andlinger Center for Energy and the Environment, candidates will be expected to develop and teach courses relevant to the educational mission of the Center. Candidates must have the ability and motivation to develop a vigorous independent research program, and to participate in collaborative efforts with faculty in the department.

Review of applications will begin December 14, 2012. Please submit C.V., statement of research and teaching interests, and contact information for at least three referees online at https://jobs. princeton.edu, position number 1200701. The statement of research should discuss how it relates to the goals of the Andlinger Center for Energy and the Environment, other elements in the university working in energy and the environment, as well as to the current research activities in the department.

\section{NG STATE UNIVERSITY}

\section{FACULTY POSITIONS \\ Department of Materials Science and Engineering}

The Department of Materials Science and Engineering (MSE) at North Carolina State University seeks outstanding applications and nominations for new faculty at the ranks of Assistant Professor, Associate Professor and Professor. The Department is currently composed of twenty-six tenure/tenure-track faculty, seven of which joined the department in 2011. The Department has traditional strengths in electronic/optical materials and structural materials, with emerging strength in microscopy, biological materials, computational materials, magnetic materials, and nanotechnology. Faculty with expertise in the following areas are of particular interest, though all areas of materials science and engineering will be considered:

- Phase-field, solid-mechanics, and related mesoscale and microstructure-level modeling that complements departmental strengths in atomic and multi-scale modeling and experimental efforts in microstructural, thermal and electrochemical dynamics,

- Structural metals and alloys or ceramics for high-performance applications. Structural materials for advanced energy systems is a primary

focus, including intermetallics, composites or novel nanostructured materials,

- Conducting polymers, including expertise in synthesis and characterization of conducting polymers and evaluation of their potential for incorporation into working devices.

Cross-disciplinary research activities engaging faculty in MSE or other departments at NCSU are encouraged. The new faculty will be national and international leaders in their respective fields, or on a clear trajectory to be so, and will work effectively in an interdisciplinary team with common intellectual goals. Senior candidates must have international standing, an exceptional record of publishing and external funding and a demonstrated record of scientific leadership. Junior candidates must demonstrate promise towards similar achievements. All candidates must possess a $\mathrm{PhD}$ in MSE or a related discipline at the time of appointment and the ability to teach at the undergraduate and graduate levels in MSE. Candidates with exceptional communication skills and the ability and commitment to work in synergistic, interdisciplinary research programs are preferred.

Nominations should include the name, address, telephone, and email contacts for the nominee along with a brief letter addressing the nominee's qualifications. Applicants should submit a cover letter, research plan, teaching plan, complete curriculum vitae, and the names and contact information of at least three references. Applications will be reviewed as they are received. The positions will remain open until suitable candidates are identified. All nominations and applications should be submitted electronically via jobs.ncsu.edu, position number 4741. Specific information about the positions can be obtained via e-mail to Justin_Schwartz@ncsu.edu.

North Carolina State University is an equal opportunity and affirmative action employer. In addition, NC State University welcomes all persons without regard to sexual orientation. Individuals with disabilities desiring accommodations in the application process should contact (919) 515-3148. 


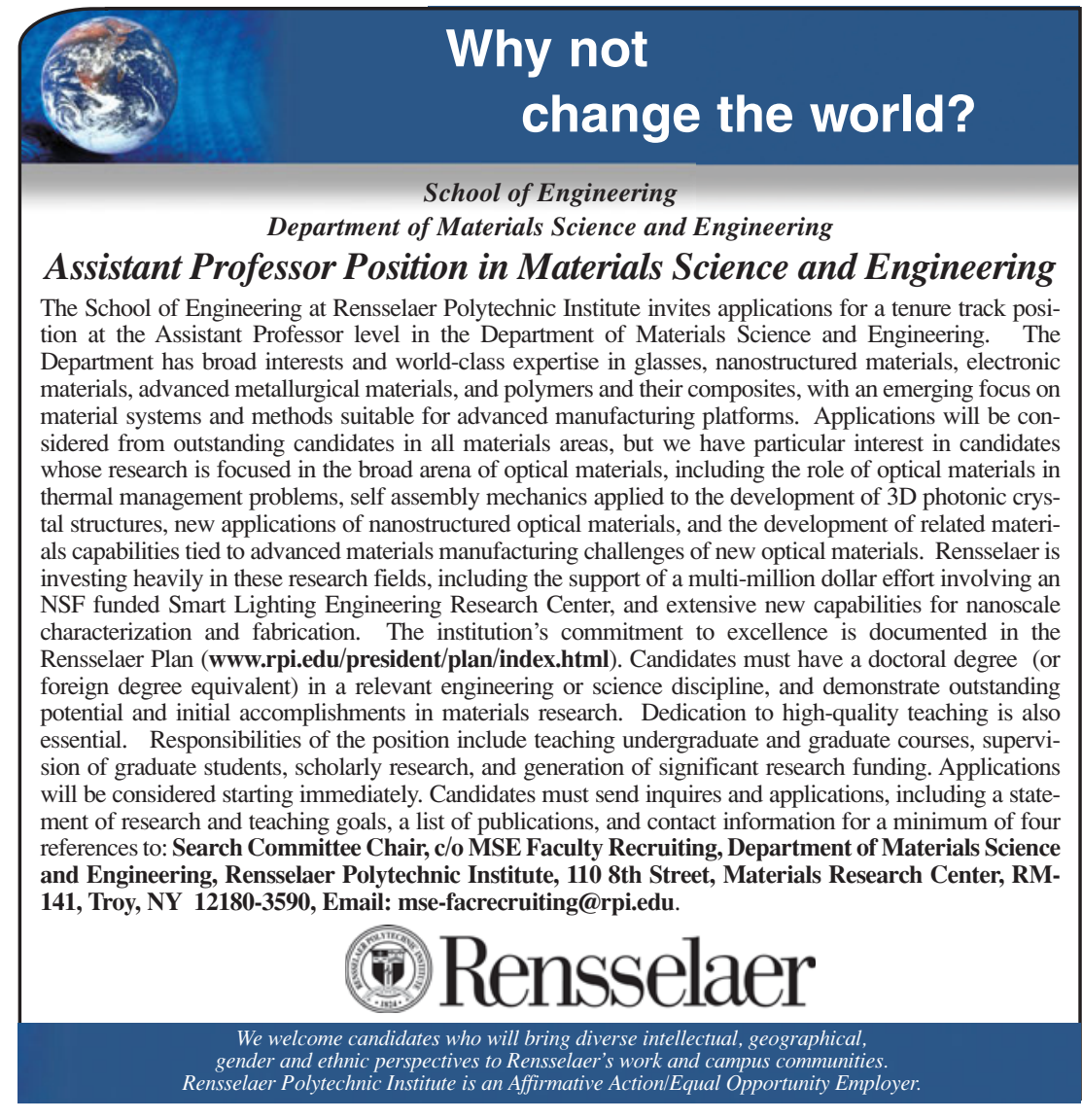

TENURE-TRACK ASSISTANT PROFESSOR

\section{Materials Science}

The Department of Mechanical Engineering and Materials Science in the George R. Brown School of Engineering at Rice University, located in Houston, Texas, invites applications for a tenure-track position in materials science at the Assistant Professor level, with an expected start date of July 1, 2013.

We seek an individual who has demonstrated excellence in one of the following areas in materials science: (1) Computational materials science from ab-initio to continuum methods with specific focus on: functional ceramics; electrochemistry; magnetic materials. (2) Advanced structural characterization techniques including but not limited to: electron microscopy; X-ray techniques; scanning probe techniques. Preference will be given to the overall originality and promise of the candidate's work rather than to the sub-area of research. Exceptional candidates with other expertise will also be considered. A successful candidate will hold a PhD degree, or will have fulfilled the $\mathrm{PhD}$ requirements by November 1 of the year employment commences, in a closely related discipline.

Applicants are expected to teach undergraduate and graduate courses. Successful applicants must also have a strong commitment to, and potential for excellence in, teaching, research, and service.

Applications should include a detailed curriculum vita that includes a list of publications, a brief statement of research and teaching interests, and the names of at least four references with references' postal and email addresses, and telephone and fax information. Applications should be sent to msfacultysearch@rice.edu or to the following address:

Search Committee Chair-Materials Science

Department of Mechanical Engineering and Materials Science

Rice University, MS 321

6100 Main Street

Houston, Texas 77005-1892

Candidates from under-represented groups, including women, are encouraged to apply. This position will be kept open until filled but priority will be given to applications received before December 1, 2012. The position is at the Assistant Professor level but exceptional candidates at higher levels may apply. For information about the Department, visit our website at http://www.mems.rice.edu/.

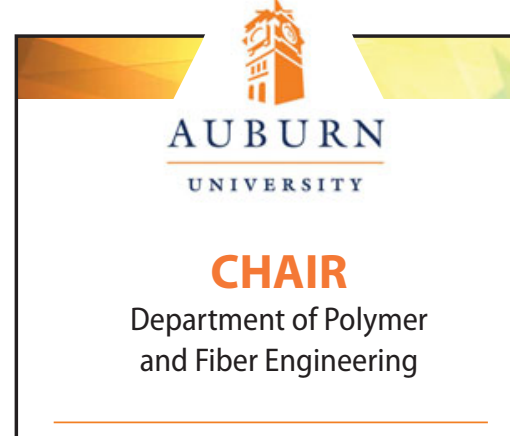

The Samuel Ginn College of Engineering at Auburn University invites applications for the position of Chair of the Department of Polymer and Fiber Engineering. The initial appointment is for a five-year term, renewable for consecutive terms. The Department Chair is responsible for providing leadership in research, teaching, and outreach. Successful candidates must possess a distinguished record of teaching, research, and scholarship, as well as excellent interpersonal skills and leadership qualities.

Consistent with the goals of the College of Engineering, applicants must articulate a clear vision and demonstrate the qualities necessary to lead a dynamic faculty toward a higher level of excellence. The Department Chair must have the academic and professional qualifications to be awarded tenure at the rank of Associate or Full Professor. A substantial record of research and scholarly achievements with a national reputation is essential along with a strong commitment to teaching and service. The successful candidate should have a record of research excellence and demonstrated leadership in an area that enhances current and emerging strengths of the department including (but not limited to): advanced polymeric systems and processing, composites, nanostructured materials, and biomedical materials. Research approaches that integrate modeling and experimentation are highly desired.

The Department of Polymer and Fiber Engineering has nine faculty members and offers undergraduate degrees in two tracks: polymer and fiber, as well as MS and PhD degrees in polymer and fiber engineering. The Polymer and Fiber Engineering faculty have a strong track-record of scholarly research and publications.

Review of applications will begin on January 15 , 2013 and continue until the position is filled. The candidate selected for this position must be able to meet eligibility requirements to work in the United States at the time appointment is scheduled to begin and continue working legally for the proposed term of employment.

To assure full consideration, applications should be submitted as a single pdf file via email to pfenchairsearch@eng.auburn.edu and must include a curriculum vita, a letter of interest providing a summary of qualifications for the position, and the names and contact information for three references.

Auburn University is an equal opportunity/affirmative action employer. Women and minorities are encouraged to apply. 


\section{RUTGERS \\ THE STATE UNIVER
OF NEW JERSEY}

FACULTY POSITION Materials Science and Engineering

The Materials Science and Engineering Department seeks to hire a tenure-track faculty member who (1) has research experience and training (experimental and/ or theoretical) in fields generally encompassed by: glass and amorphous materials, optical and photonic materials, ceramics, geology, mineralogy, or related, and (2) who is enthusiastic about building a thriving research program in glass science and innovative applications aimed at solving critical global problems.

Preference will be given to candidates at the Assistant Professor level, however outstanding candidates at higher ranks will also be considered. The successful candidate will have completed their PhD degree prior to the start of employment and be able to undertake the normal faculty roles of research, teaching, and service. The MSE Department is an integral component of Materials and Nanotechnology research being conducted at Rutgers under the auspices of the IAMDN (Institute for Advanced Materials, Devices, and Nanotechnology). Active alignment/affiliation in IAMDN by the successful candidate would be strongly encouraged.

The MSE Department is part of the School of Engineering, which enrolls nearly 4000 undergraduate and graduate students, and has 140 full time faculty, 70 staff, 11 research centers, and 7 academic departments. With more than $\$ 56$ million in annual research expenditures the Rutgers School of Engineering is one of the premier public institutions in its class. Whether through sustainability, manufacturing, the biomedical sciences, transportation or energy, Rutgers' Engineers, now more than 20,000 strong, are addressing some of the most important issues in our society and identifying new ways to solve tomorrow's problems.

Applications should be emailed as a single, merged, PDF file that includes: (1) a cover letter with pertinent facts about your experience and background, (2) a detailed glass science/technology research plan, (3) a one-page teaching philosophy statement, and (4) a full CV. Three letters of reference should also be solicited simultaneously (sent from the referees directly to the Search Committee Chair at the email address below). Review of applications will begin November 30, 2012.

MSE Search Committee Chair

Department of Materials Science and Engineering

Email: MSE2012@jove.rutgers.edu

Rutgers University is an Equal Opportunity/Affirmative Action employer. Rutgers is an ADVANCE institution, one of a limited number of universities in receipt of NSF funds in support of our commitment to increase diversity and the participation and advancement of women in the STEM disciplines.
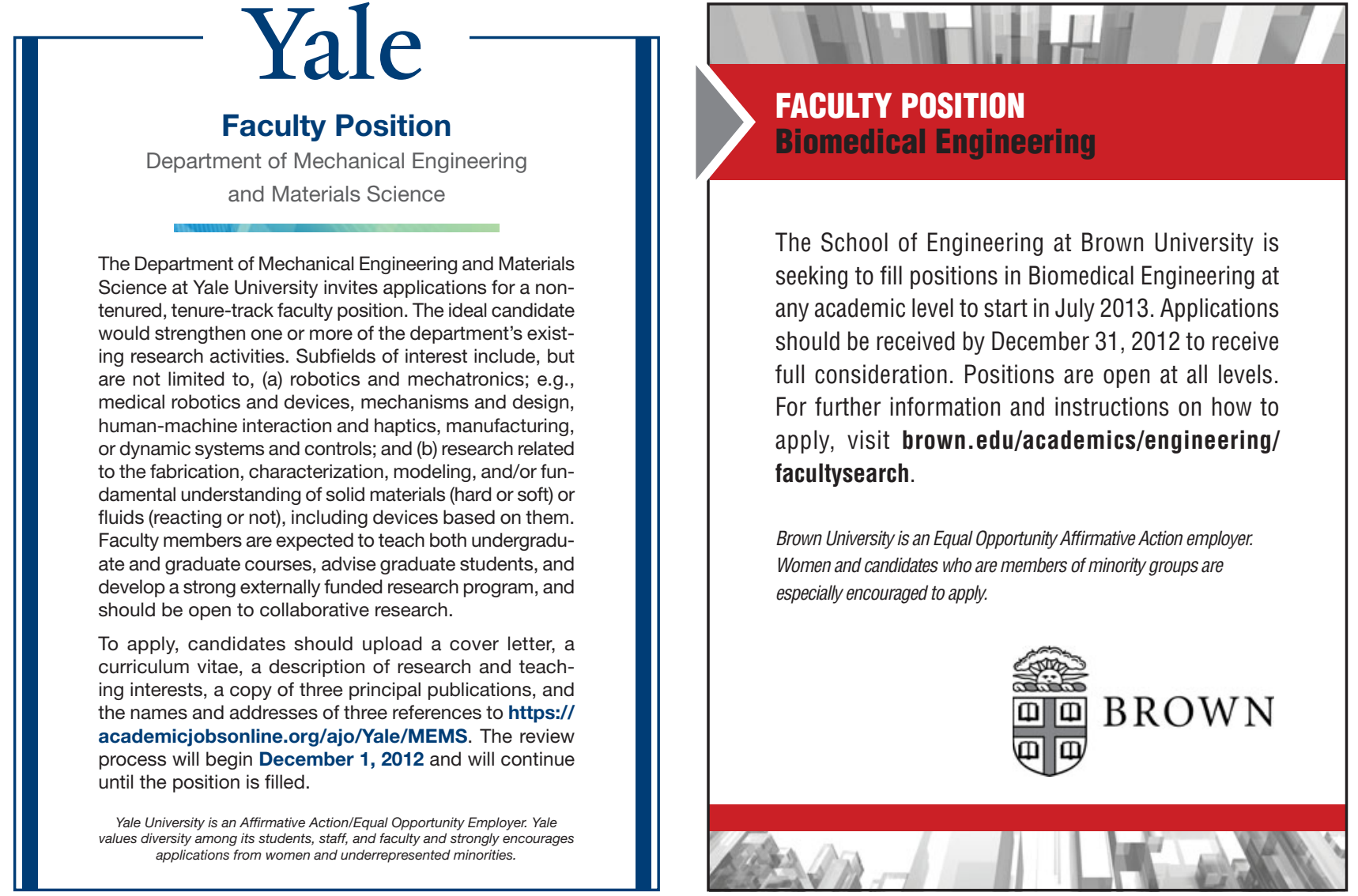


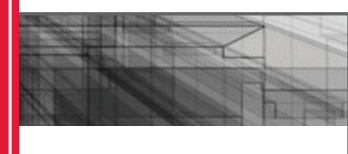

PROFESSOR AND DEPARTMENT CHAIR

Department of Mechanical Engineering

The Department of Mechanical Engineering at Boston University is accepting applications for the position of Department Chair and Professor, with tenure, starting ideally by September 1, 2013.

The Department currently has 42 primary faculty members (35 tenured or on tenure track), with many holding secondary appointments in other departments and divisions within the College. Undergraduate and graduate enrollments are approximately 500 and 150 respectively. ME faculty also advise almost 100 graduate students enrolled in programs based in other departments and the divisions. Our BS degree in ME allows for optional departmental concentrations in aerospace engineering and manufacturing engineering and college-wide concentrations in energy technologies, nanotechnology, and technology innovation. At the graduate level, the ME Department offers research and professional Masters' degrees in both mechanical and manufacturing engineering and the $\mathrm{PhD}$ in mechanical engineering.

Boston University has made a long-term commitment to the development of the College of Engineering and that commitment is having results. The College is ranked 38th in the nation (USN\&WR) and 21st in research funding per faculty. With annual expenditures of over $\$ 8$ million, the ME Department's research focus areas include: robotics, control, MEMS and nanotechnology, physical and biomedical acoustics, materials science and engineering, energy and energy systems (including thermofluid sciences), micro-fluidics, biomechanics, advanced manufacturing technologies, and computational mechanics. The portfolio is strengthened by the department's affiliation with the Division of Materials Science and Engineering, the Division of Systems Engineering, the Fraunhofer USA Center for Manufacturing Innovation, the Center for Information and Systems Engineering, and the Photonics Center.

The successful candidate will have an earned doctorate and be internationally recognized for research excellence, leadership and scholarship in mechanical engineering or a related discipline. Additionally, s/he will have a sound vision for the future of the Department and the disciplines it represents, the skill to lead and advance a research-oriented department, the ability to both recruit and mentor exceptional junior faculty, and a passion for educational excellence at the undergraduate and graduate levels. The new Chair will be expected to oversee the hiring of multiple new faculty members over the next five years as one aspect of implementing their vision for the future. The Department is particularly interested in a leader who will further strengthen the graduate program through an environment that fosters interdisciplinary research and industry collaboration. More information on the Department can be found at www.bu.edu/me/.

Applications will be considered until the search committee has identified a suitable list of viable candidates. It is unlikely that applications received after January 15, 2013 will be considered. Applicants should submit an electronic dossier that includes a cover letter, curriculum vitae, and the names and addresses of at least six references to mechairsearch@bu.edu.

Boston University is an Equal Opportunity and Affirmative Action employer.

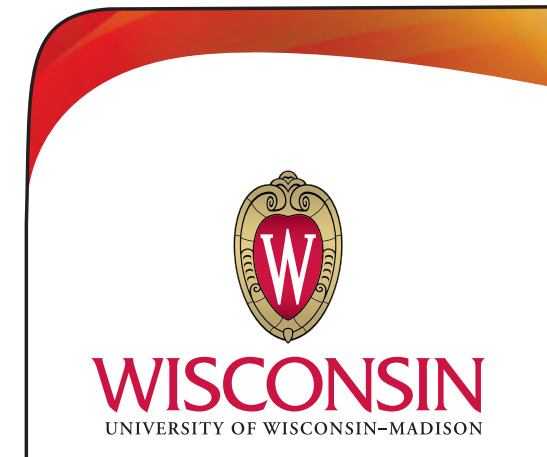

\section{FACULTY POSITIONS \\ Materials Science and Engineering}

The Department of Materials Science and Engineering at the University of WisconsinMadison seeks new faculty at the Assistant, Associate, and Full Professor levels. Distinguished candidates with outstanding records of achievement will be considered for the $Y$. Austin Chang Chair in Materials Science and Engineering.

Successful candidates will develop an internationally recognized research program, demonstrate leadership in attracting extramural funding, dedicate themselves to excellence and innovation in both undergraduate and graduate education, and provide service to the profession. We seek outstanding faculty pursuing research in the areas of advanced materials (including biomaterials, ceramics, metals, polymers), materials processing, and phase transformations.

UW-Madison offers world-class research opportunities, interdisciplinary collaborative research centers, and exceptional facilities for materials characterization, computation, and nanofabrication (www.engr.wisc.edu/ mse/facultysearch). The University is committed to assisting candidates in achieving the highest levels of accomplishment.

Applicants for tenure-track positions must provide plans for teaching and research in materials science and engineering (each two pages maximum), a curriculum vitae, and three letters of reference. Candidates for tenured positions must provide curriculum vitae, teaching and research statements, and contact information for five references. All materials should be sent electronically to mse.applications@engr.wisc.edu. To ensure full consideration applications must be received by January $\mathbf{1 5}, \mathbf{2 0 1 3}$. Unless confidentiality is requested in writing, information regarding applicants must be released upon request. Finalists cannot be guaranteed confidentiality.

UW-Madison is an equal opportunity/affirmative action employer. 


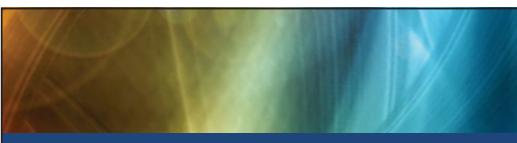

\section{FACULTY POSITION}

\section{Department of Materials Science and Engineering}

The Department of Materials Science \& Engineering at Drexel University (www.mse.drexel.edu) is seeking applications for a tenured/tenure-track faculty position. Of particular interest are candidates with a demonstrated record of excellence in original research in either:

(1) soft and hybrid material design, synthesis, assembly, and function, or

(2) electrochemistry with emphasis in energy storage.

A PhD degree in Materials Science and Engineering or a closely related field is preferred.

The ideal applicant should also possess research interests in an emerging research area such as advanced energy technologies, biomedical materials and devices, or environmental sustainability, and be able to contribute to building an interdisciplinary, integrated research program focused in their area of expertise.

Applicants should submit a cover letter; a full curriculum vitae; statements of research and teaching plans; and names and contact information of three references online at http://www.materials. drexel.edu/faculty/positions/. If a female candidate is selected at the Assistant Professor level, she will be eligible for the Anne Stevens Assistant Professorship. The position is available immediately and applications will be considered until the position is filled.

Drexel University is an Equal Opportunity Employer and encourages applications from qualified women and minorities.

\section{Materials Science and Engineering}

\section{FACULTY POSITIONS \\ Department of Materials Science and Engineering}

The Department of Materials Science and Engineering (DMSE) seeks candidates for open tenure-track faculty positions to begin July 2013 or thereafter. Appointments would be at the assistant or untenured associate professor level. In special cases, a senior faculty appointment may be possible. Faculty duties include teaching at the graduate and undergraduate levels, research, and supervision of student research.

Candidates should hold a PhD degree in Materials Science and Engineering or a related field by the beginning of the appointment period. Candidates with deep knowledge of the core of Materials Science and Engineering are desired. DMSE seeks to broaden its research portfolio in several key areas, including: materials selection and materials economics, microstructure characterization and design, materials chemistry and surface science, photonic and optical materials. Research portfolios that cut across these areas and other aspects of materials science and engineering are desired. However, the present search is broadly defined and applicants with expertise in any and all areas of materials science and engineering are encouraged to apply. MIT has a number of institute-wide initiatives underway or in development, on topics that include Manufacturing, Energy, Environment, and Health. Individuals who can connect to these initiatives are of interest.

Interested candidates should submit application materials electronically at https://school-of-engineering-faculty-search.mit.edu/dmse/. Each application should include: a curriculum vitae, a statement of research interests, and a statement of teaching interests. We request that each candidate arrange for three letters of reference to be uploaded at https://school-of-engineering-faculty-search. mit.edu/letters/.Questions should be addressed to DMSE-Search-Master@dmsefacsrch.mit.edu. Responses received by December 31, 2012, will be given priority.
Senior Executive Service Career Opportunity

\section{ES-806, 1301, or 1310: $\$ 119,554$ to $\$ 179,700$ per annum*}

*Actual salary may vary depending on the scope and complexity of the position and the qualifications and current compensation of the selectee.

Become a member of an elite research and development community involved in basic and applied scientific research and advanced technological development for tomorrow's Navy and for the Nation.

The Superintendent of the Materials Science and Technology Division located at the Naval Research Laboratory, Washington, DC, is responsible for the oversight of approximately 172 employees (including government, contract, and post doctorate fellows), most of whom are professional scientists and engineers. The Division consists of: the Multifunctional Materials Branch, the Materials and Sensors Branch, The Center for Computational Materials Science, and the Special Projects Group. Division research is at the frontiers of materials science and technology and encompasses the intrinsic behavior of metals, alloys, ceramics, glasses, and composites and their performance and reliability in Naval structures and devices. The ultimate goal is to provide materials knowledge that enables new and/or improved military performance that lead to transformational capabilities. The Division has an annual budget of over \$38 million. The Superintendent is responsible for:

- Technical and administrative management of a broad program of highly sophisticated basic and applied research and exploratory and advanced development of materials; and technical management of industrial contract programs which provide new and improved materials for new weapons systems

- Overall planning and direction of a coordinated research and development program related to materials science designed to meet the present and future needs of the Navy;

- Obtaining support for work of the various Division programs, stimulating interest and activity on the part of the Division personnel, and providing creative thinking, suggestions and judgments with respect to major research encountered;

- Acting as principal consultant to the Navy, other agencies and nations on the science and developing applications for the research programs under his/her cognizance.

Applicants should be recognized as national/international authorities and should have planned and executed difficult programs of national significance that show outstanding attainment in the field of materials science.

For information regarding this vacancy and specific instructions on how to apply, go to www.usajobs.gov and enter the following announcement number: NW2XXXX-00-752920K9464770-S. The announcement closes on 30 November 2012. Contact Ginger Kisamore at ginger. kisamore@nrl.navy.mil if you need additional information. E-mailed resumes cannot be accepted. 
FACULTY POSITION

Electrochemical Energy Storage and Conversion

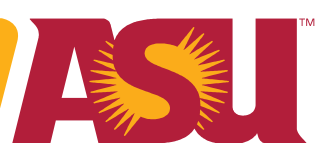

The Ira A. Fulton Schools of Engineering at Arizona State University seek applicants for a tenure-track/tenured faculty position in electrochemical energy storage and conversion. Areas of interest focusing on the important thrust area of energy include physical electrochemistry, electrochemical theory/computation, and polymer science.

Faculty research in the Fulton Schools of Engineering in the area of electrochemical energy storage and conversion connects to a variety of topics that includes surface/interface physics and thermodynamics, physical electrochemistry, thin films, lithium-ion batteries, electrochemical capacitors, photocatalytic processes, and nanoporous metals. Collaborative possibilities exist not only within the Fulton Schools of Engineering but also across the university, including Lightworks (http://asulightworks.com) and the Global Institute of Sustainability (http://sustainability.asu.edu). The current opening is intended to broaden our expertise and expand collaborations.

The successful candidates will hold an earned PhD degree, or equivalent, in Materials Science and Engineering, Chemical Engineering, or a related field. Required qualifications also include demonstrated evidence of research capability and commitment to teaching excellence as appropriate to the candidate's rank.

Faculty members are expected to develop an internationally recognized and externally funded research program, develop and teach graduate and undergraduate courses, advise and mentor graduate and undergraduate students, and undertake service activities

Appointments will be at the assistant, associate, or full professor rank commensurate with the candidate's experience and accomplishments, beginning August 2013. Although the faculty appointment may be anywhere in the Fulton Schools of Engineering, the Materials Science and Engineering and Chemical Engineering programs are currently the most involved in electrochemical energy storage and conversion.

Review of applications will begin November 1, 2012; if not filled, reviews will occur on the 1st and 15th of the month thereafter until the search is closed. To apply, please submit as a single PDF file a current CV, statements describing research and teaching interests, and contact information for three references to electrochemical.faculty@asu.edu.

Current information regarding the position is available at http://engineering.asu.edu/facultypositions.

Arizona State University is an equal opportunity/affirmative action employer. Women and minorities are encouraged to apply. ASU's complete non-discrimination statement is available at https://www.asu.edu/titlelX/.

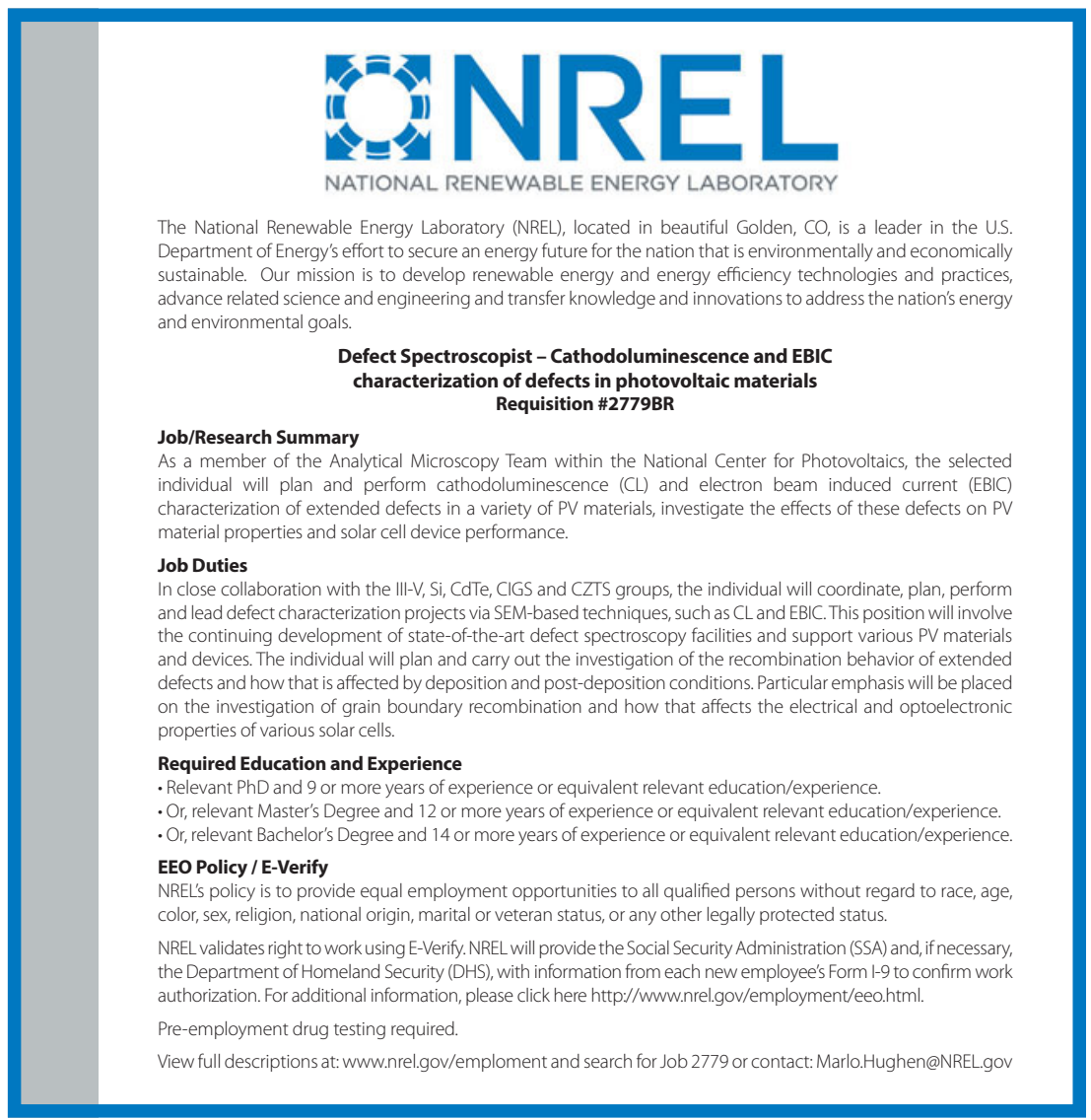

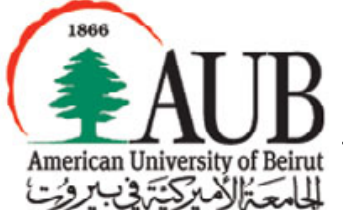

FACULTY POSITION

Materials Science and Engineering

The Faculty of Engineering \& Architecture at the American University of Beirut invites applicants for a full time faculty position in Materials Science and Engineering. The search is open for candidates with expertise in Materials Science and Engineering with research interests in one or more of the areas of ceramics, high temperature steel, nanomaterials, composites, polymeric materials, or innovative building materials. This position will be at the assistant professor rank but exceptionally qualified candidates with established research and teaching credentials will be considered at higher ranks.

The successful candidate must (a) have a PhD degree in Materials Science and Engineering or a closely related discipline, (b) be able to develop a strong research program, and (c) demonstrate a strong record of independent research and publications.

The successful candidate is expected to teach graduate and undergraduate courses, participate in program development, and be active in research. The candidate is expected to take an active role in developing research initiatives leading to external funding and publications in internationally recognized journals, and should have the ability to work in a team-oriented environment. The selected candidate will be primarily housed in the department that best matches her/ his qualifications with a strong possibility of joint appointments with other departments.

Applications will be reviewed as received and the process will continue until the position is filled. Salary is commensurate with education and experience. Information about the faculty can be found at www.aub.edu.lb/fea.

Kindly send a letter of application that includes a brief statement that articulates your teaching philosophy and research plans, curriculum vitae, and the names and contact information for three references, to the Dean of Engineering and Architecture, Faculty of Engineering and Architecture, the American University of Beirut, P.O. Box 11-0236, Riad El-Solh, Beirut 1107-2020, Lebanon. Applications can also be submitted by e-mail to fea@aub.edu.lb.

The American University of Beirut is an Affirmative Action, Equal Opportunity Employer. For more information consult the AUB home page at www.aub.edu.lb. 


\title{
TENURE-TRACK/TENURED FACULTY POSITIONS
}

\author{
Department of Materials Science and Engineering
}

Search Code: ENG101012MSE

The College of Engineering at The University of Texas at Arlington is building areas of excellence that foster cross-disciplinary, cutting edge research. The Department of Materials Science and Engineering (MSE) is recruiting one or more outstanding faculty in these areas of excellence, including biomaterials and material/bio interfaces and/or advanced materials for nano/micro electronics. Candidates with research specializations in other related materials areas will also be considered.

An earned doctorate degree in a core engineering or science discipline is required. Candidates must have demonstrated a commitment to quality teaching and scholarly research. Applicants in senior ranks are expected to have an excellent record of research, scholarship, funding, and leadership, and a commitment to teaching and mentoring. A successful candidate is expected to develop sponsored programs that promote discovery, learning, and engagement. Opportunities exist for collaborative research with UT Arlington research centers, programs, and local industry partners. The positions are interdisciplinary and the candidates must demonstrate an ability to work with faculty in science and engineering. Competitive salaries and research startup funds are available for these positions.

UT Arlington is a doctoral, research-extensive university with a current enrollment of over 33,000 students and is part of the University of Texas System. The University is located in Arlington, Texas, in the Dallas/Fort Worth Metroplex, which is home to top clinical and teaching hospitals in the nation. It has the largest concentration of hightech industry in the State of Texas and second in the nation after Silicon Valley. With more than 4,500 students and 23,000 alumni, the College of Engineering (uta.edu/ engineering) is the fourth largest in Texas, and has ties to numerous high technology companies in North Texas. The College offers nine baccalaureate, 13 masters, and nine doctoral degree programs.

The MSE Department (uta.edu/mse) is primarily a graduate program that offers master's and doctorate degrees with excellent research facilities and a campus-wide, state-of-the-art Materials Characterization Center for Materials and Biology (ccmb.uta.edu). It has eight faculty members and more than 70 graduate students. Additional research opportunities exist at the Nanotechnology Research and Education Center (NanoFab, uta.edu/nano) and the UT Arlington Research Institute (UTARI, uta.edu/utari).

Review of applications will begin on November 1, 2012, and continue until January 15, 2013.

The successful candidate will be required to complete an Employment Eligibility Verification form and provide documents to verify identity and eligibility to work in the U.S. UT Arlington is an Affirmative Action/Equal Opportunity Employer. Women, minorities, veterans, and individuals with disabilities are encouraged to apply. The use of tobacco products is prohibited on UT Arlington properties. A criminal background check will be conducted on finalists.

To Apply: www.uta.edu/engineerapply

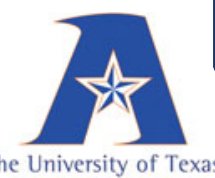

ARLINGTON

\section{and National Nuclear Security Administration Stewardship Science Graduate Fellowship}

Providing outstanding benefits and opportunities to students pursuing a Ph.D. in areas of interest to stewardship science:

- properties of materials under extreme conditions and hydrodynamics

- nuclear science

- high energy density physics

\section{BENEFITS}

- $\$ 36,000$ yearly stipend

- Payment of full tuition and required fees

- \$1,000 yearly academic allowance

- Yearly conferences

- 12-week research practicum

- Renewable up to four years

\section{APPLICATIONS DUE JANUARY 16, 2013} www.krellinst.org/ssgf

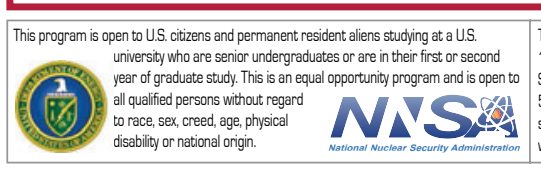

\section{The Krell Institute}

1609 Golden Aspen Drive,

Suite 101, Ames, IA 50010 • 515.956 .3696 ssgfakrellinst.org uww.krellinst.org/ssgf

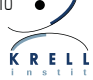

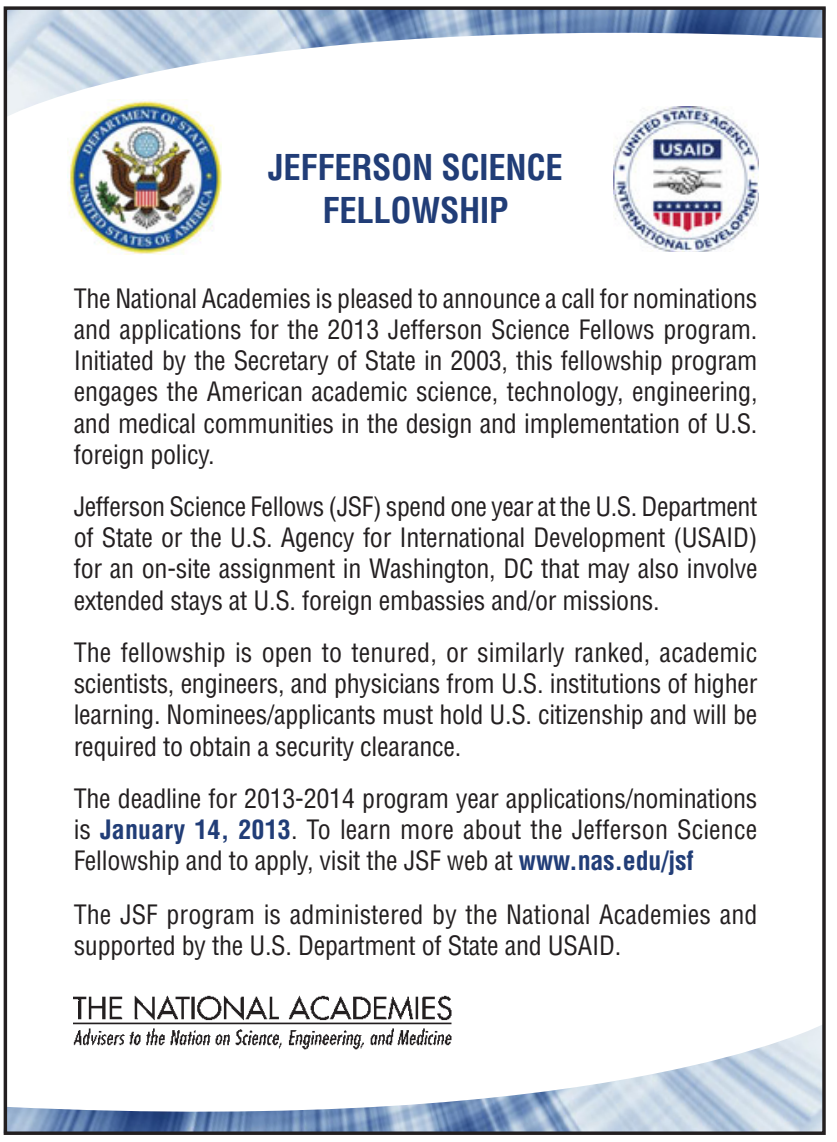




\section{Seeking Expert in Quality Engineering}

Johanson Technology, a leading manufacturer of ceramic capacitors, has an immediate opening for this key position.

\section{In this role you will:}

- Drive root cause analysis to ensure product quality/reliability

- Complete follow through of internal and external corrective actions

- Complete system and process audits; follow up of action items

- Develop inspection procedures and sampling plans

- Train inspection staff for receiving, inprocess, and final inspection

- Train employees in quality tools and statistical methodology

- Lead problem-solving teams and utilize advance problem-solving techniques; i.e., DOE, FMEA, PCP and GR\&R

- Support Mil-qualification, maintenance, and reliability test/ prediction program

- Maintain the Quality Information System

- Be responsible for writing and revising procedures

Qualification requirements:

- BS Degree (Electronics, Industrial Engineering, or Quality preferred)

- Hands on experience with SPC

- Thorough knowledge and experience with ISO 9000, AS9100

- Extensive training in Quality Fundamentals

- Experience with components

- Self-starter and work independently

Additional Pluses

- CQE

- Hands on experience with Microsoft Access

Johanson is proud to be an Equal Opportunity Employer and offers a competitive compensation package which includes: free life insurance and an excellent $401 \mathrm{~K}$ match! To learn more about the company please check our website at johansontechnology.com.

For immediate consideration, please email resume to jobs@ johansontechnology.com.

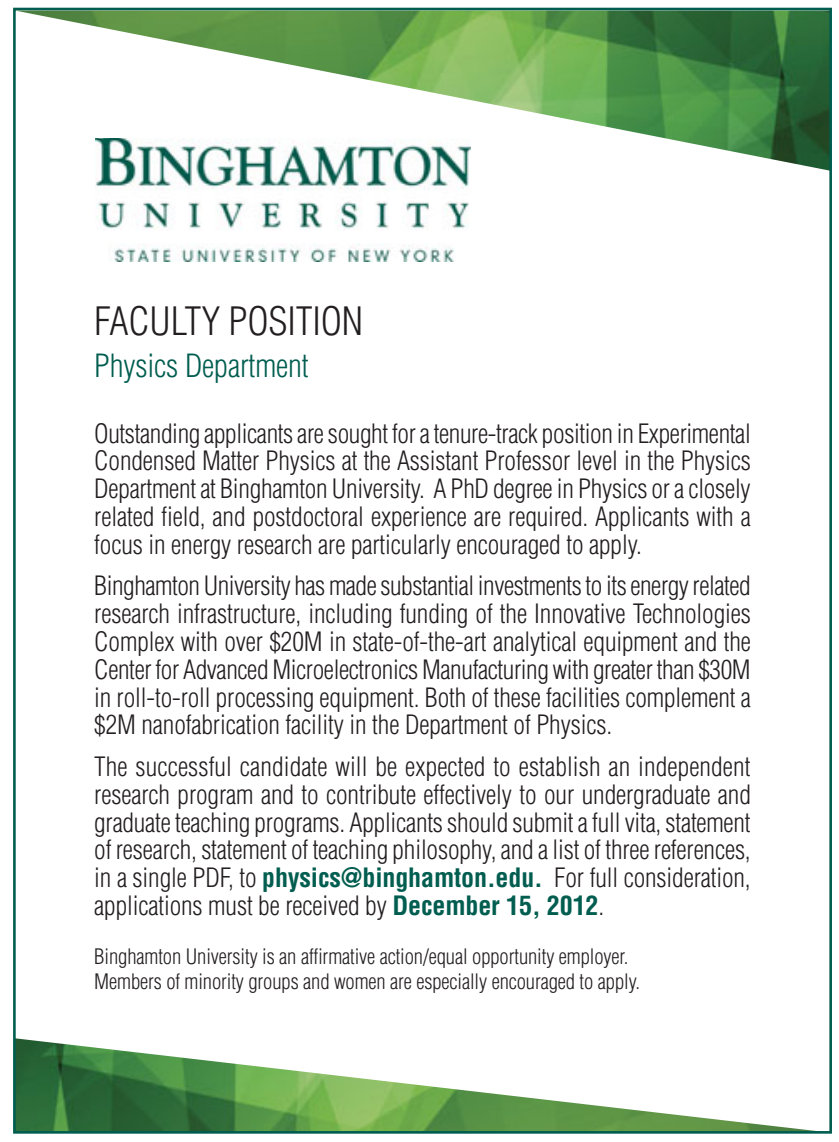

\section{BOSTON UNIVERSITY}

FACULTY POSITION

Division of Materials Science and Engineering

The Division of Materials Science and Engineering (MSE) at Boston University (BU) is seeking candidates for a junior level faculty position. All areas will be considered, but we have a particular interest in experimental approaches to the digital design of materials. The ideal candidate would work in an interdisciplinary way with theorists, computational scientists, and other experimentalists. S/he will create a new type of materials science where one predicts, grows, measures, and then confronts the predictions with the experimental results, with the goal of being able to discover new materials and new science digitally. The Division is seeking to foster growth in the broad, interdisciplinary topics of biomaterials, electronic, and photonic materials, materials for energy/environment, and nanomaterials. Candidates with research interests that transcend the traditional boundaries of MSE are strongly encouraged to apply.

MSE is a unique divisional program at BU with excellent experimental and high-end computational resources. The Division has national and international prominence for its exceptional research and education record. MSE is an interdisciplinary program with faculty from Mechanical/Electrical-Computer/Biomedical Engineering, Physics, Chemistry, BU Medical School, BU Dental School, and other BU entities. Outstanding collaboration opportunities are available with nationally recognized medical centers and universities/colleges, nearby research centers, and industry throughout the Boston area.

Qualified candidates must possess a relevant, earned PhD degree and have the ability to teach effectively, to develop funded research programs in their area of expertise, and to contribute to the tradition of excellence in research that is characteristic of the MSE Division. Self-motivated individuals who thrive on challenge and are eager to utilize their expertise to strengthen and grow an ambitious program are desired. Women, minorities, and candidates from other underrepresented groups are especially encouraged to apply to help us continue building an exceptional 21st century university environment. The expectation is that the suitable candidate will have the appropriate experience and interests to hold a tenure-track appointment in one or more BU departments, particularly in our Mechanical, Electrical and Computer, or Biomedical Engineering Departments, in addition to the appointment in the Materials Science and Engineering Division.

Beyond its research and academic activities, BU has a lively, urban campus situated along the banks of the Charles River in Boston's historic Fenway-Kenmore neighborhood. The campus and surrounding areas offer limitless opportunities for recreational activities, from world-class art and performances to sporting events and fine dining.

Please visit http://www.bu.edu/mse/ for more information about the MSE Division. To apply, please visit and follow application instructions online at https://academicjobsonline . org/ajo/BU/MSE/ASTP. Application deadline is January 15, 2013. Review of applications will begin immediately; therefore applicants are encouraged to apply early. 


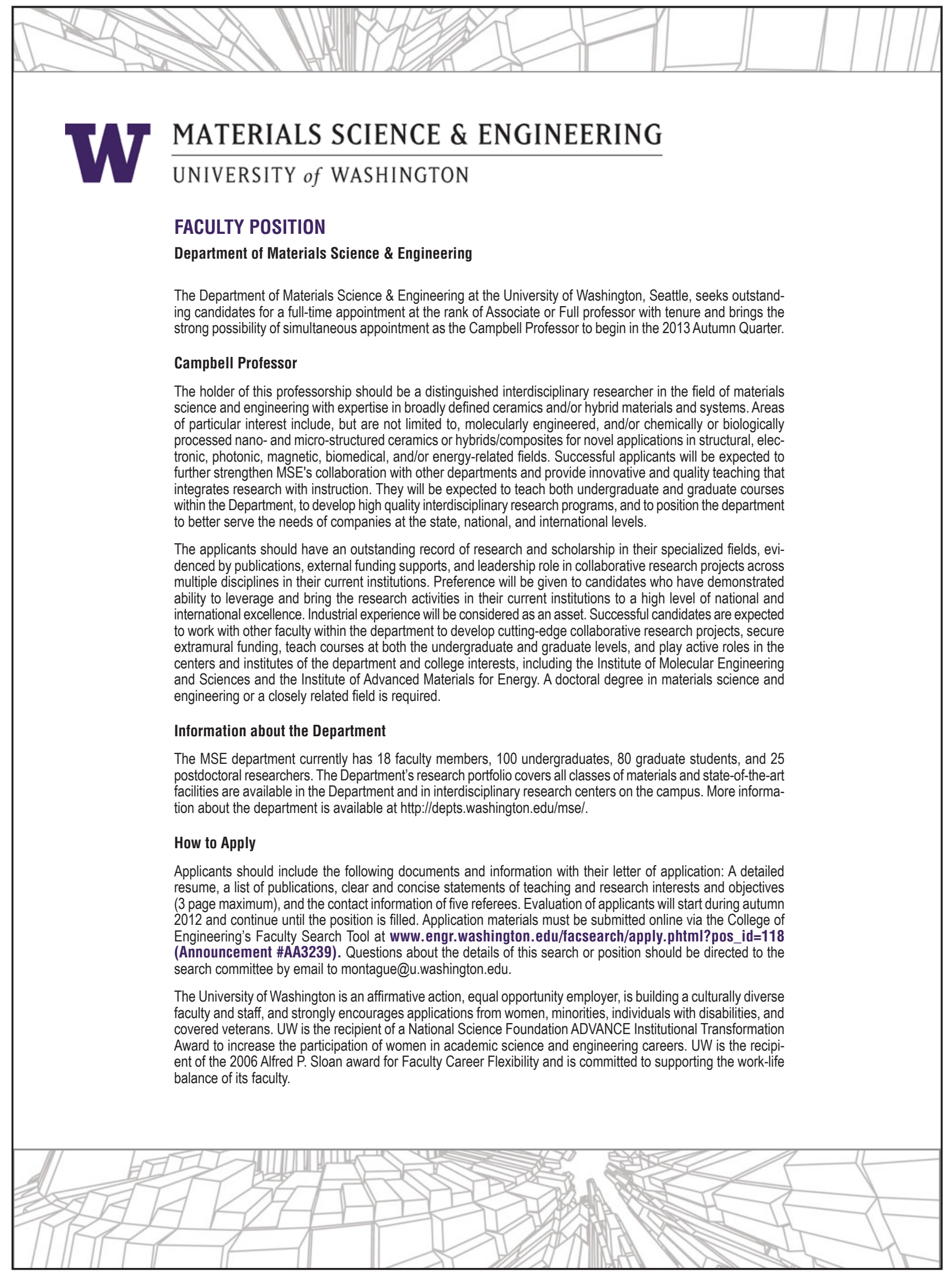




\section{STRATEGIC FACULTY RECRUITMENT

\author{
Materials for Energy Production, Conversion, \\ Storage and Utilization
}

The President and the Provost of the Florida State University are pleased to announce a major interdisciplinary initiative in the area of Energy and Materials with an initial focus on materials for energy production, conversion, storage, and utilization. To launch this strategic effort as many as eight tenure-track/ tenured faculty positions will be filled. This faculty search is open with respect to rank and academic department. Successful candidates are expected to have a synergistic impact on existing research programs in the University's departments and interdisciplinary centers as well as develop new areas. Sustained pursuit and growth of collaborative, externally-funded research programs is an explicit goal.

Strengths at the Florida State University include energy-related materials programs in Chemistry, Physics, and Scientific Computing in the College of Arts and Sciences, and in Mechanical, Industrial \& Manufacturing, Electrical \& Computer, and Chemical \& Biomedical Engineering in the College of Engineering. Complementing these programs are interactive centers including the National High Magnetic Field Laboratory, the Applied Superconductivity Center, the High Performance Materials Institute, the Aero-Propulsion, Mechatronics and Energy Center, and the Center for Advanced Power Systems. Linking these colleges and centers is a new PhD program in Materials Science and Engineering. Robust, department-based doctoral programs in materials and related areas are also present at the University.

The Florida State University is classified as a very high research activity, doctorategranting institution with a student population approaching 41,000 . Last year the University granted over 400 doctoral degrees and had more than $\$ 220 \mathrm{M}$ in research expenditures. In recent years, the University has made considerable investments in research infrastructure in the sciences and engineering disciplines The University is located in Tallahassee, the Capital of Florida, where residents have access to a broad range of cultural amenities afforded by the presence of three institutions of higher learning. The region is relatively undeveloped with close proximity to the Apalachicola National Forest, an abundance of springs, lakes and rivers as well as pristine beaches and the adjacent waters of the Gulf of Mexico.

We invite nominations for and applications from researchers active in broadlydefined areas of materials for energy production, conversion, storage, and utilization including theory, computation, synthesis, fundamental materials characterization, devices, and testing and proof of concept and prototype. Successful candidates will be offered highly competitive salaries and start-up packages, state-of-theart research space and access to world-class instrumentation, computing, and facilities in academic and interdisciplinary units.

Applicants are asked to provide in .pdf format a letter of application, a full curriculum vitae, the names and contact information of three professional references, and a two page narrative describing their research interests that should include a clear statement as to how the candidate would complement this inter-college effort at Florida State University. Full applications must be sent electronically to materials.search@fsu.edu. Nominations should be sent to the same address. Review of applications and nominations will begin on December 1, 2012. Additional information about the materials programs at FSU and this faculty search can be obtained at http://www.research.fsu.edu/materials_search/.

The Florida State University is committed to the diversity of its faculty, staff, and students, and to sustaining a work and learning environment that is inclusive. Women, minorities, and people with disabilities are encouraged to apply. FSU is an Equal Opportunity/Access/Affirmative Action Employer.

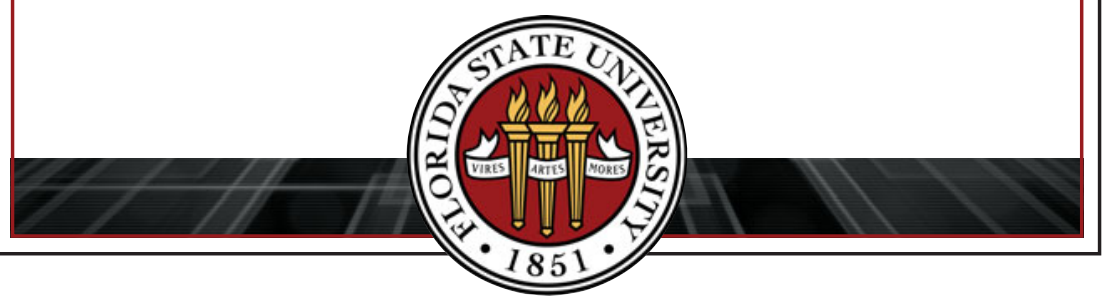

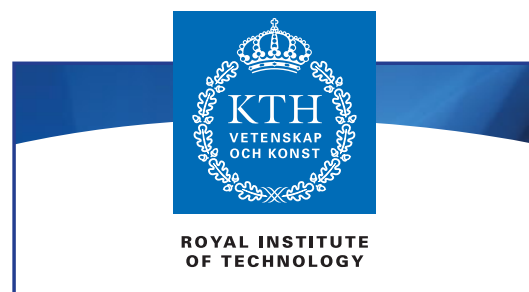

\section{FULL PROFESSOR}

\section{Functional Materials}

The KTH School of Information and Communication Technology, ICT, seeks one Professor in Functional Materials.

KTH in Stockholm is the largest and oldest technical university in Sweden. Education and research spans from natural sciences to all branches of engineering and includes architecture, industrial management, and urban planning. There are a total of just over 15,000 first and second level students and more than 1,600 doctoral students. The school of Information and Communication Technology, ICT, conducts research and education at leading international level in material physics, photonics/optics, electronic systems, integrated devices and circuits, as well as communication systems (www.kth. se/en/ict).

The subject area includes synthesis and characterization of functional materials. Special emphasis is put on materials, particles, and phases of nano dimension.

We expect the new professor to build and manage a world-leading research group and to develop excellent education in the subject area. A Professor at KTH must have documented experience of being able to independently lead, conduct, and develop education and research of a high international quality. He shall have demonstrated scholarly and teaching skills within the subject area.

Criteria for assessment are as follows: Broad knowledge and understanding of functional materials, with significant knowledge of materials of nano dimensions, are central criterions for the candidate assessment. Documented understanding of electron microcopy is considered to be of importance. Of special relevance are proven capabilities to build up a first class international research program, to successfully recruit and supervise graduate students. An additional criterion is documented ability to interact with the society and to inform about research and development. The capacity for scientific cooperation with research groups within and outside the home university and skills in transferring research results into industrial applications are also of great importance.

The application deadline is December 14, 2012. For complete and official information about the position and for application procedures, please visit www.kth.se/en/om/ work-at-kth/vacancies. 